\title{
Movilidad Cotidiana y Cambio Modal en Zonas Urbanas de Baja Densidad. Estudio de Caso en la Región Metropolitana de Barcelona
}

\author{
Day-to-Day Mobility and Modal Changes in Low-Density Urban Areas. Case Study \\ of the Metropolitan Region of Barcelona \\ Àngel Cebollada \\ angel.cebollada@uab.cat @ https://orcid.org/0000-0002-4925-2896 \\ Anna Badía \\ anna.badia@uab.cat @ https://orcid.org/0000-0001-9660-9811 \\ Ana Vera \\ ana.vera@uab.cat @ https://orcid.org/0000-0001-7865-1610
}

Departament de Geografia, Universitat Autònoma de Barcelona.

C/ de la Fortuna, s/n. Edifici B. Facultat de Lletres, UAB. 08193 Bellaterra (Cerdanyola del Vallès)

\section{INFO ARTÍCULO}

Recibido: $10 / 6 / 2019$

Revisado: 19/12/2019

Aceptado: 08/01/2020

\section{PALABRAS CLAVE}

Movilidad Cotidiana

Baja Densidad

Cambio Modal

Colectivos Sociales

\section{KEYWORDS}

Daily Mobility

Urban Low-Density

Modal Change

Social Groups

\section{RESUMEN}

El artículo aborda el estudio de la movilidad cotidiana en las áreas urbanas de baja densidad bienestantes con el objetivo de detectar colectivos pioneros en los cambios en las pautas de movilidad. Se ha utilizado metodología cualitativa y se han realizado entrevistas semiestructuradas en una muestra de residentes en el municipio de Matadepera (Barcelona). Los resultados muestran la preminencia del vehículo privado y la poca permeabilidad de las nuevas prácticas de movilidad (activas y compartidas) que ya se entrevén entre sectores sociales similares en las zonas urbanas densas. La morfología urbana y el diseño de un espacio público totalmente sesgado para el uso del vehículo privado dificultan el cambio en los modos de desplazamiento. Se precisan políticas públicas que posibiliten la creación de proximidad y rediseñen el espacio público para crear las condiciones que favorezcan cambio modal.

\begin{abstract}
The current researech deals daily mobility in urban low-density welfare society areas in order to identify pioneers in modal shift. Qualitative methodology was used; semi-structured interviews were conducted in a sample of residents in the municipality of Matadepera (Barcelona Region). The results show the prominence of the car in the daily life and the low permeability of the new mobility practices (active and shared) that similar social groups begin to practice in dense urban areas. The urban morphology and the design of a public space biased for the use of the private vehicle make difficult the modal change. Public policies are needed to make it possible to create proximity and redesign the public space to generate the conditions for modal change.
\end{abstract}




\section{INTRODUCCIÓN}

Sin duda, uno de los principales retos, sino el principal de las sociedades del primer tercio del siglo XXI es encajar nuestro estilo de vida dentro de los límites ecológicos y ambientales del planeta. Si bien las advertencias de los impactos del modelo social y sus consecuencias futuras ya eran conocidas desde hace décadas (Meadows et al., 1972), en la segunda década del milenio las evidencias son más manifiestas y están identificadas e incluso cuantificadas: las recurrencias de fenómenos climáticos extremos debidos al cambio climático, la sobremortalidad por contaminación atmosférica (Lelieveld, et al., 2019) y el aumento de las migraciones ambientales (Castillo, 2011) son ejemplos de ello. Ante esta situación, la necesidad de una profunda transición socioecológica de nuestras sociedades se hace más urgente (Prats et al., 2017) y en esta transición, la reorganización de la movilidad cotidiana de la población deberá tener un gran protagonismo.

\subsection{Movilidad y territorio urbano}

Gran parte de la responsabilidad de la crisis ambiental se debe al binomio ciudad y movilidad. Efectivamente, las dinámicas urbanas se han caracterizado por un proceso simultáneo que puede resumirse en:

- especialización funcional del territorio, que separa los distintos usos urbanos y aleja físicamente las distintas esferas de la vida cotidiana,

- el crecimiento en baja densidad de las áreas residenciales,

- la desigualdad en la distribución de los servicios urbanos,

- la segregación social en el territorio urbano, agrupando en el espacio a colectivos con características sociales comunes,

- la continuada construcción de infraestructura para el uso del vehículo privado.

Todo ello ha supuesto el aumento de las distancias a recorrer en los desplazamientos cotidianos, especialmente en los laborales (Pooley y Turnbull, 1999) y la pérdida global de autocontención de los municipios, entendida esta como la capacidad de retener en su seno los desplazamientos que tienen su origen en él (Nel·lo et al., 2002). Las necesidades crecientes de movilidad se han cubierto con el uso del vehículo privado (Braçe, 2018) con el consecuente aumento de los impactos ambientales, especialmente las emisiones de gases contaminantes en la atmósfera (Mendiola et al., 2014).

Estas emisiones contribuyen al proceso de cambio climático y derivan directamente en la salud de las personas; es significativo el interés que desde la investigación de salud pública se da a la movilidad cotidiana como lo muestra la aparición de revistas específicas sobre este tema como el Journal of Transport \& Health. Las investigaciones se encaminan, entre otros temas, hacia el conocimiento de las patologías a causa de la contaminación ambiental, la cuantificación de muertes prematuras que esto supone en las áreas urbanas y la reducción de años de vida potenciales que las sociedades urbanas asumen por este hecho. La misma Organización Mundial de la Salud muestra también su interés por este tema (WHO, 2016).

Pero para estudiar las pautas de movilidad y sus impactos en las áreas urbanas deben distinguirse las diferentes partes, definidas a partir de la densidad urbana. Por esto se distinguen dos tipos de zonas urbanas. Por un lado, están los espacios compactos, centrales, densos y diversos, en muchas ocasiones herederos de la ciudad compacta tradicional. En el otro extremo se encuentran los espacios de periferia, de baja densidad, monofuncionales y con una gran dependencia del vehículo privado y que son los espacios urbanos que han crecido más, tanto territorial como demográficamente en los últimos decenios.

Por lo que hace a la movilidad, es en las áreas centrales donde mayores esfuerzos se han dedicado, tanto desde las administraciones públicas como en el interés académico. Es en estos espacios compactos y diversos donde se realizan múltiples transformaciones para avanzar hacia el horizonte de la descarbonización. Para ello se peatonalizan las calles, se refuerza el transporte público que a veces cuenta con la (re)introducción del tranvía, se procura fortalecer la idea de vida de barrio como unidad de pertenencia y cotidianidad de las personas (Delclòs y Miralles-Guasch, 2018) y se (re)introduce la escala humana siguiendo los postulados 
de urbanistas como Gehl (2010). En definitiva, se asiste a un proceso de pacificación de la ciudad central y de recuperación de un espacio para las personas y la vida urbana. Un buen ejemplo de ello son las supermanzanas en Barcelona (Rueda, 2017). Asimismo, es en estos espacios centrales donde se experimentan las innovaciones (sociales y tecnológicas) en el ámbito de la movilidad: nuevas formas de compartir el automóvil o la comprensión de la movilidad como servicio serían algunas de las más relevantes (Fàbregas y Villalante, 2017).

En la otra cara de la moneda encontramos los espacios metropolitanos que Antonio Font (2007a) denomina paisajes de baja densidad, desconectados de los tejidos urbanos compactos. Como se ha anunciado, el mayor aumento de la superficie urbanizada se ha producido de esta forma; el informe de la Agencia Europea de Medio Ambiente muestra cómo este proceso de dispersión (sprawl) urbana es una característica del crecimiento urbano de los últimos decenios del ssiglo XX rompiendo así con las formas de producción de ciudad de Europa hasta aquel momento (EEA, 2006).

A una escala más local, Muñoz (2007) comprueba que la producción de vivienda residencial en la región metropolitana de Barcelona' posterior al 1980 ha sido en gran parte unifamiliar; ya en 1992 más del 50\% del territorio residencial producido en este ámbito territorial era de esta tipología edificatoria, con el elevado consumo de suelo que supone. En una misma línea, Mendiola (2011) encuentra cómo las dinámicas territoriales en Vizcaya en el último decenio del siglo XX se caracterizan por el fuerte aumento de las viviendas unifamiliares y concentradas en los municipios menores de la provincia.

Pero bajo el concepto de baja densidad se encuentran distintas modalidades de realidades urbanas. $Y$ entre ellas, una de las principales es la conocida como "urbanización". Font (2007b, 104-105) la define como "un tipo de asentamiento característico de algunas regiones urbanas euromediterráneas, como organizaciones residenciales de baja densidad, compuestas por viviendas unifamiliares (aisladas, pareadas o más recientemente en hilera)". Según el mismo autor, se da una gran heterogeneidad de urbanizaciones por las características sociales de sus moradores puesto que encontramos tanto de rentas altas con viviendas de lujo hasta de rentas bajas con casas de autoconstrucción.

Solo en la provincia de Barcelona, Barba y Mercadé (2006) identificaron 806 urbanizaciones en total, que ocupaban 26.080 ha $\left(260 \mathrm{~km}^{2}\right)$ y estimaron que había 192.000 parcelas, 93.500 viviendas y un potencial para 100.000 viviendas más y 500.000 residentes. En 2015, la comarca del Vallès Occidental, donde se ubica Matadepera, tenía 98 urbanizaciones con una superfície de 3.885 ha (un 6,7\% del total) (Departament de Territori i Sostenibilitat, n.d.).

Probablemente, la existencia de estos nuevos espacios urbanos supone unos de los principales retos para afrontar el proceso de transición ecológica de los entornos metropolitanos. Las lógicas con que se construyeron estas urbanizaciones (muchas de las cuales al margen de las normativas urbanísticas) no responden a los criterios de los que se ha definido como ciudad sostenible. Es común que toda la literatura sobre estos espacios señale la insuficiencia de servicios urbanos, la gran dependencia del vehículo privado, la dificultad de establecer un transporte colectivo, la pobreza del espacio público, y el débil vínculo social e identitario con el propio municipio (Naredo, 2007). En definitiva, las urbanizaciones carecen de proximidad: los quehaceres propios de la vida cotidiana no pueden resolverse en el entorno inmediato. Con el uso del coche y la realización de las actividades fuera del vecindario la escala de barrio desaparece (Casanovas y Gutiérrez, 2012) y con ella la referencia de la escala más próxima de los espacios relacionales personales (Solana et al., 2016).

De hecho, los datos cuantitativos sobre el reparto modal en los espacios metropolitanos muestran una dualidad territorial. Así se asiste a un doble proceso en las pautas de movilidad: mientras en los entornos centrales y compactos, con políticas de pacificación del tráfico y políticas de mejora del transporte público y de los medios activos el uso del coche disminuye, en las áreas dispersas de las conurbaciones su uso aumenta. En el caso andaluz, Braçe (2018) ve cómo la movilidad al trabajo de un municipio de la periferia sevillana (Mairena del Ajarafe) alcanza más del 75\% de los desplazamientos. Este fenómeno ha sido estudiado en

1. La región metropolitana de Barcelona es un área funcional donde se concentra la mayor parte de población y actividades económicas y es uno de los ámbitos de planeamiento territorial de Cataluña. Matadepera se localiza dentro de esta demarcación. 
distintas ciudades francesas y muestran cómo en un periodo de 30 años (1987 - 2016), para el caso de Lille, el uso del automóvil disminuyó un 34\% en el centro mientras que en su área metropolitana aumentó un $38 \%$. La evolución de los medios activos, a pie i en bicicleta, ha tenido una evolución contraria mientras que los transportes públicos aumentaron en ambas áreas, aunque de una forma más importante en el centro (Richier y Rabaud, 2018).

Teniendo en cuenta las distintas tipologías que componen los espacios metropolitanos, Kaufmann (2000) identifica cuatro modos de vida (modes de vie) según las características urbanas y las posibilidades de uso de los distintos medios de transporte: ciudadano, rural, metropolitano y californiano. Mientras el primero y el tercero corresponden a las áreas urbanas densas, el segundo y el cuarto se asocian a los paisajes urbanos de baja densidad. El modo de vida rural podría corresponderse con antiguos núcleos que han quedado incorporados a las dinámicas urbanas pero que mantienen una cierta cohesión y posibilidad de vida cotidiana en su seno (lo que sería la cabecera del municipio) con modos de movilidad activos, aunque las conexiones externas se realizan principalmente con el uso del coche. El modo de vida californiano, absolutamente dependiente del vehículo privado para resolver cualquier necesidad del quehacer diario, corresponde a las urbanizaciones.

\subsection{Movilidad y colectivo social}

Si bien la morfología urbana interviene en las pautas de movilidad de la población, dichas pautas también se diferencian por el colectivo social de pertenencia. Género, edad, nacionalidad o renta constituyen variables explicativas del uso de los modos de transporte. Así está ampliamente estudiado cómo mujeres y hombres presentan diferencias significativas en la forma de moverse cotidianamente en el territorio (Miralles-Guasch, 2010). También la edad o la nacionalidad ha sido objeto de análisis (Cebollada, 2009). Asimismo, tradicionalmente se ha asociado rentas altas con índices de motorización mayores y, por ende, con un mayor uso del coche (García Palomares, 2008). Autores como García (1999) describen el automóvil como bien posicional y como símbolo de status y analiza las pautas de movilidad de los grupos de renta alta en Valencia. Considera que son los grupos con más capacidad de influir en los comportamientos de la población, lo que permite explorar las posibilidades de un cambio modal. Kingley y Urry (2011) estudian cómo a lo largo del siglo XX se ha naturalizado el automóvil en los entornos urbanos y cómo, más que un medio de transporte, se ha convertido en un símbolo.

Pero en el marco de la crisis ecológica y la extensión del uso del vehículo a gran parte de la sociedad, se revisa el papel del coche como bien posicional. Al contrario, la literatura académica relaciona cada vez más a ciertos colectivos de rentas altas y con un estilo de vida cosmopolita con el uso de la bicicleta, que ahora se interpreta como símbolo y modo de desplazamiento urbano, en detrimento del coche para un uso cotidiano y continuado (Stehlin, 2015).

Pero por lo que se desprende de la literatura académica, el análisis de la movilidad según colectivo social se enmarca en territorios concretos, ya que, si bien la relación con los medios de transporte está condicionada por la variable social de pertenencia, también lo está por la localización espacial de residencia. Así, se relaciona la emergencia de nuevas narrativas de movilidad, y con ello de nuevos hábitos, en las zonas centrales de la ciudad con los colectivos bienestantes.

Pero pocos indicios aparecen en la literatura académica sobre la emergencia de nuevos discursos de la movilidad en los colectivos bienestantes residentes en zonas de baja densidad. Anotaciones como las de Héran $(2018,277)$, que relata cómo los habitantes de ciertas áreas de las periferias urbanas empiezan a reclamar mejoras en el espacio público para facilitar la marcha a pie. La difusión de estas reclamaciones se da en forma de mancha de aceite empezando en la "péripheries bourgeoises" que han sido todavía poco estudiadas.

Este artículo tiene como objetivo conocer las percepciones y las pautas de movilidad de los residentes en las áreas urbanas bienestantes de baja densidad. Con ello, se pretende identificar nuevas actitudes que propicien un cambio de los modos de movilidad. Las preguntas de investigación son: 
- ¿Cuáles son las pautas de movilidad de los residentes?

- ¿Qué percepciones y expectativas tienen acerca de la movilidad?

- ¿Qué factores explican los hábitos de movilidad?

- ¿Las nuevas narrativas de la movilidad (modos activos como el desplazamienro a pie o en bicicleta, medios compartidos...) están presentes en el imaginario y vida cotidiana de estos residentes?

\section{METODOLOGÍA}

En primer lugar, se realizó un análisis de datos secundarios del municipio de Matadepera principalmente a partir de las estadísticas oficiales como el INE (Instituto Nacional de Estadíctica) y el IDESCAT (Institut d'Estadística de Catalunya), pero también de la consulta de los planes de ordenación municipal, así como de los planes derivados. Siempre se trabajó con los datos más recientes; que en este caso cabe mencionar la inexistencia de datos estadísticos sobre movilidad a escala municipal desde el año 2001. Para completar la información, en especial la de la oferta, se consultó a los operadores de transporte del municipio, así como la revista local (la Gaseta) para rastrear la actualidad y las actuaciones en el territorio. Con ello se caracterizó el área de estudio.

Para el estudio de caso se optó por utilizar la metodología cualitativa. Como señalan autores como Rodríguez et al (1996), Valles (1997) y Ruiz (1996) esta metodología es apropiada para el estudio de la estructura de los fenómenos sociales y en la identificación de las narrativas (existentes y emergentes) en este estudio indígena sobre las prácticas cotidianas de la movilidad. Se realizaron 15 entrevistas semiestructuradas a residentes de las urbanizaciones del municipio, suficientes al redundar la información obtenida. La técnica de reclutamiento ha consistido en la conocida como bola de nieve (tras realizar la primera entrevista se le pide ayuda para identificar otras personas que tengan las mismas características) y se han seguido criterios de localización residencial de manera que estuvieran representados todos los sectores de las urbanizaciones; las distancias desde los respectivos domicilios hasta el centro del casco urbano oscilan entre 1,5 km el más próximo hasta 7,6 km el más alejado. Tal como puede observarse en el cuadro 1, todas las personas entrevistadas pertenecen al mismo colectivo social. Así, la mayoría tienen estudios superiores, y están laboralmente activos (excepto dos). Todos los activos desempeñan cargos de dirección o son técnicos o profesores y el puesto de trabajo se encuentra, mayoritariamente, fuera del municipio. Asimismo, el rango de edad oscila entre los 44 años y los 61 con hijos e hijas en edades de instituto y, en algunos casos, primeros años de universidad. En todos los hogares hay al menos dos vehículos.

Cuadro 1. Características de las personas entrevistadas.

\begin{tabular}{|l|l|l|l|c|l|c|c|c|}
\hline Código & Género & Edad & Formación & $\begin{array}{c}\text { Distancia al } \\
\text { centro }\end{array}$ & $\begin{array}{l}\text { Municipio de } \\
\text { trabajo }\end{array}$ & $\begin{array}{c}N^{\circ} \text { coches en } \\
\text { el hogar }\end{array}$ & $\begin{array}{c}\text { No motos en } \\
\text { el hogar }\end{array}$ & $\begin{array}{c}\text { Residentes } \\
\text { en el hogar }\end{array}$ \\
\hline D1 & Mujer & 44 & Medios & $1,7 \mathrm{~km}$ & $\begin{array}{l}\text { Castellar del } \\
\text { Vallès }\end{array}$ & 2 & 0 \\
\hline D2 & Mujer & 47 & Superiores & $5 \mathrm{~km}$ & Barcelona & 3 & 0 & 4 \\
\hline D3 & Hombre & 53 & Superiores & $1,7 \mathrm{~km}$ & Barcelona & 3 & 0 & 4 \\
\hline D4 & Hombre & 52 & Superiores & $4,6 \mathrm{~km}$ & $\begin{array}{l}\text { Sant Cugat } \\
\text { del Vallès }\end{array}$ & 2 & 0 & 5 \\
\hline D5 & Hombre & 43 & Superiores & $2,5 \mathrm{~km}$ & Barcelona & 2 & 0 & 5 \\
\hline D6 & Mujer & 50 & Superiores & $3,6 \mathrm{~km}$ & Terrassa & 2 & 0 & 5 \\
\hline D7 & Hombre & 42 & Superiores & $1,7 \mathrm{~km}$ & $\begin{array}{l}\text { Cornellà de } \\
\text { Llobregat }\end{array}$ & 3 & 5 \\
\hline
\end{tabular}




\begin{tabular}{|c|c|c|c|c|c|c|c|c|}
\hline Código & Género & Edad & Formación & $\begin{array}{c}\text { Distancia al } \\
\text { centro }\end{array}$ & $\begin{array}{l}\text { Municipio de } \\
\text { trabajo }\end{array}$ & $\begin{array}{c}N^{\circ} \text { coches en } \\
\text { el hogar }\end{array}$ & $\begin{array}{c}N^{0} \text { motos en } \\
\text { el hogar }\end{array}$ & $\begin{array}{l}\text { Residentes } \\
\text { en el hogar }\end{array}$ \\
\hline D8 & Mujer & 45 & Básicos & $1,7 \mathrm{~km}$ & Matadepera & 2 & 0 & 5 \\
\hline D9 & Mujer & 47 & Superiores & $5,4 \mathrm{~km}$ & Inactiva & 2 & 0 & 6 \\
\hline D10 & Mujer & 48 & Superiores & $1,5 \mathrm{~km}$ & Terrassa & 2 & 1 & 4 \\
\hline D11 & Hombre & 60 & Medios & $2,5 \mathrm{~km}$ & Matadepera & 2 & 0 & 4 \\
\hline D12 & Mujer & 50 & Superiores & $4,4 \mathrm{~km}$ & Terrassa & 2 & 1 & 4 \\
\hline D13 & Mujer & 61 & Superiores & $3 \mathrm{~km}$ & Jubilada & 3 & 0 & 2 \\
\hline D14 & Hombre & 55 & Superiores & $3 \mathrm{~km}$ & Terrassa & 3 & 0 & 3 \\
\hline D15 & Mujer & 50 & Superiores & $7.6 \mathrm{~km}$ & Matadepera & 1 & 0 & 4 \\
\hline
\end{tabular}

Fuente: Elaboración propia a partir del trabajo de campo.

Todas las entrevistas fueron grabadas y transcritas y la explotación de la información se llevó a cabo con el software Atlas.ti versión 8.0, para la codificación se las entrevistas así facilitar su análisis posterior. El lugar de realización fue en los domicilios particulares de las personas entrevistadas. Para garantizar el anonimato de los informantes, estos se identifican con el código utilizado para la transcripción y explotación de las entrevistas.

\section{CASO DE ESTUDIO}

Matadepera es un municipio situado en el límite de la región metropolitana de Barcelona, al pie del Parque Natural de Sant Llorenç del Munt i l'Obac (figura 1). El crecimiento demográfico se inicia en los años 1970 con el proceso de metropolitanización cuando el municipio pasa de 1.075 habitantes a 9.186 (datos del Padrón para 2017). En aquellos momentos, Matadepera ya abandonaba el carácter rural y se consolidaba claramente la especialización residencial con la aparición de segundas residencias para los sectores más pudientes de las ciudades industriales de la región metropolitana (Aguilar, 2012), especialmente de Terrassa (que dista tan solo a tres kilómetros) y en menor medida Sabadell (a cinco kilómetros de distancia). Esta tradición residencial para los sectores de grupos sociales favorecidos se ha mantenido hasta nuestros días. Así, según el Censo de 2011, el 42\% de la población mayor de 16 años del municipio contaba con estudios superiores (el doble que Catalunya). Asimismo, en 2016, la renta por habitante era superior a la media de la Comunidad Autónoma en un 50\% (IDESCAT, 2016) y según el ranquing de la Agencia Tributaria es el segundo municipio español con mayor renta bruta media, solo por detrás de Pozuelo de Alarcón.

El área urbana de Matadepera se compone de urbanizaciones de baja densidad con un predominio de viviendas unifamiliares, mayormente aisladas (Muñoz, 2005), insertadas en un entorno básicamente forestal. El $70 \%$ del parque de viviendas supera los $120 \mathrm{~m}^{2}$ cuando el peso de estas viviendas en el conjunto del parque en Catalunya apenas alcanza el $12 \%$.

La distribución territorial de la población es bastante homogénea por toda el área urbana, compuesta por 22 urbanizaciones y barrios. Si bien es cierto que el casco antiguo cuenta con más residentes (2.139 habitantes, el 22,9\% del total), existen varias urbanizaciones alejadas del centro urbano con poblaciones que oscilan entre los 500 y los 1.000 residentes. Matadepera presenta una estructura de edades relativamente joven y poco envejecida: la cantidad de menores de 14 años es mayor que la población mayor de 65 años, a diferencia de las cifras para el conjunto de Catalunya.

Según el Mapa Urbanístico de Catalunya (MUC) de 2018, el uso del suelo urbano es esencialmente residencial (véase cuadro 2). De las 456,52 ha que suman los usos residenciales, el 94,3\% corresponde a residencial aislado. En cambio, la superfície del municipio ocupada por actividades económicas es irrelevante; 
apenas 10 ha (0,40\% del total del municipio). Así no es de extrañar que mayormente la población de la localidad debe desplazarse fuera para trabajar. Algunas cifras ilustran la situación del municipio en el año 2001: la autocontención era de sólo un 20,6\%. Por el mismo motivo, la atracción de población de otros municipios por motivos laborales es reducida. El reparto modal por trabajo está monopolizado por el vehículo privado (78\%).
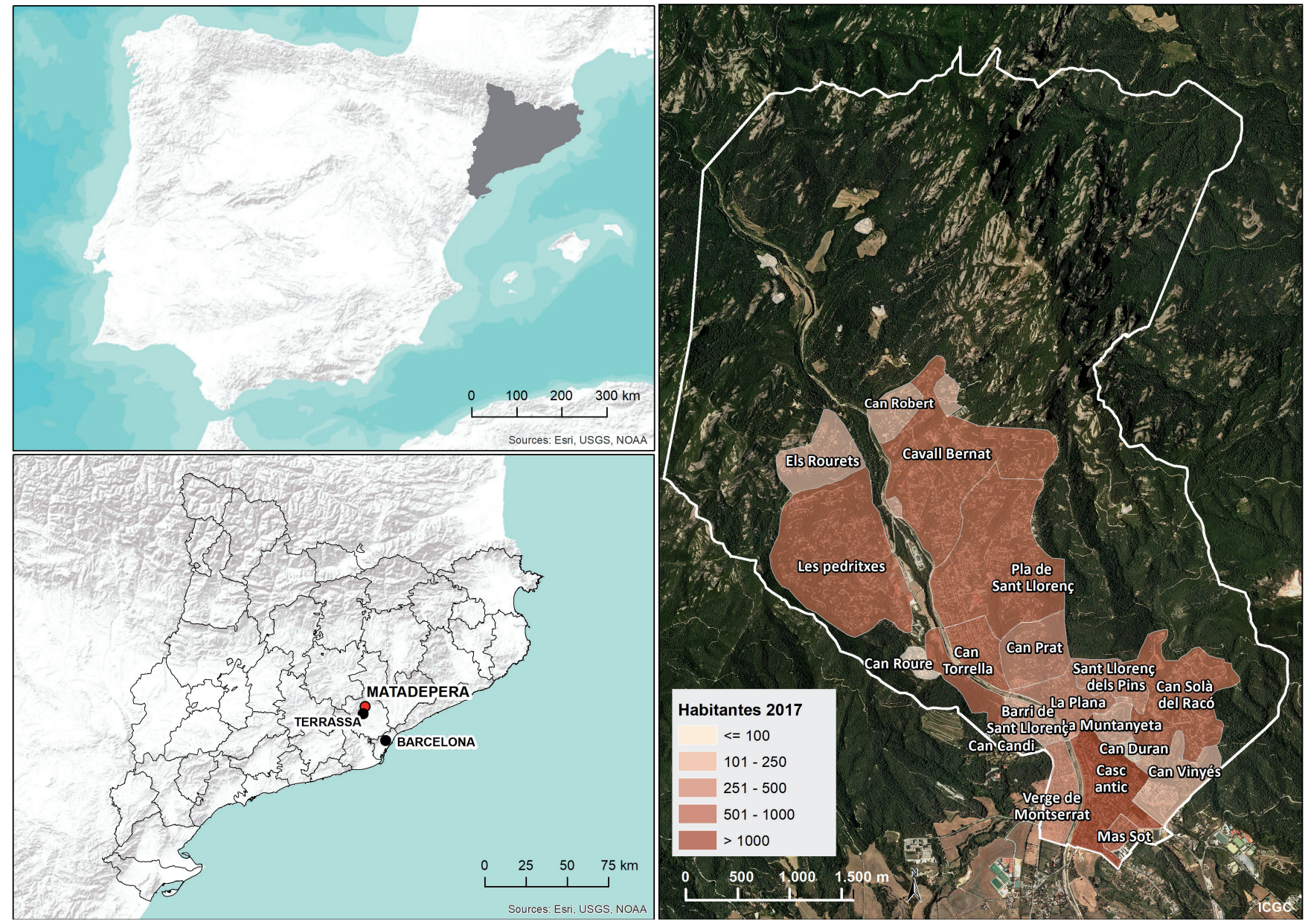

Figura 1. Localización del municipio y distribución de la población, 2017. Fuente: Elaboración propia en base a los datos de ESRI, USGS, NOAA y ICGC.

Cuadro 2. Usos del suelo, 2018.

\begin{tabular}{|l|c|c|}
\hline \multicolumn{1}{|c|}{ Usos del suelo } & ha & $\%$ \\
\hline Urbano: actividad económica & 10,11 & 0,4 \\
\hline Urbano: áreas residenciales & 456,52 & 18 \\
\hline Urbanización aislada & 430,45 & 16,97 \\
\hline Urbano: equipamientos & 35,64 & 1,41 \\
\hline Urbano: red viaria & 102,95 & 4,05 \\
\hline No urbano & 1931,04 & 76,14 \\
\hline
\end{tabular}

Fuente: Elaboración propia a partir de los datos del MUC, 2018.

El municipio no cuenta con ningún plan de movilidad. No obstante, Matadepera realizó en 2004 un Estudio de Movilidad. El Pla Estratègic 2010 contemplaba cuatro acciones relacionadas con la movilidad de las 
que tres hacían referencia al uso y mejora de la circulación en vehículo motorizado y una a la mejora del transporte público interurbano. Finalmente, el Plan de Ordenamiento Urbanístico Municipal de Matadepera (de 2009) contempla la necesidad de elaborar un plan de movilidad sin realizar en 2019.

El municipio cuenta con un parque de 517 turismos/1.000 habitantes (cifras algo superiores a la media de Catalunya). Esta cifra supone 1,5 turismos por vivienda principal.

Por lo que hace al transporte público colectivo se compone de dos líneas que conectan Matadepera con Sabadell y con Terrassa respectivamente. En el primer caso, la oferta consiste solo en tres expediciones por día en cada sentido, por lo que, como forma de transporte competitivo, es claramente insuficiente.

La línea que conecta con Terrassa, presenta más expediciones y se divide en dos sublíneas. La primera con una expedición por hora hace un recorrido por las urbanizaciones y facilita el acceso al centro de Terrassa. La segunda funciona como una lanzadera y conecta el centro de Matadepera con la estación término de Ferrocarrils de la Generalitat de Catalunya, de forma que enlaza rápidamente Matadepera con el conjunto de la región metropolitana. En este caso la frecuencia varía según horas-punta (cada 30 minutos) u horas-valle.

Para la movilidad cotidiana activa, Matadepera solo dispone de área peatonal en el casco antiguo y carece, hasta el momento, de infraestructura específica para bicicletas. A pesar de ello, existe un proyecto de enlazar Matadepera con las dos principales ciudades vecinas por medio de un carril bici.

\section{RESULTADOS Y DISCUSIÓN. PAUTAS Y PERCEPCIÓN DE MOVILIDAD DE LA POBLACIÓN}

A continuación, se exponen los resultados del análisis de las entrevistas realizadas.

\section{1. ¿Heterotopía? La percepción del entorno de residencia}

Tal como se desprende del análisis de las entrevistas, los residentes en las urbanizaciones de Matadepera son conscientes que residen en un municipio acomodado, que se caracteriza por sus rentas altas y que en cierta manera se trata de un privilegio y/o suerte residir en él. No es solamente un elemento de estatus socioeconómico, sino que esto se traduce en un entorno amable y culto que lo hace confortable para residir.

Esto por lo que respeta al municipio, después a pesar de ser una población baja, de ser un municipio con población baja y una superficie muy alta, también es de un nivel adquisitivo y nivel social realmente alto, quizás es el segundo o el primero más alto de toda Cataluña y del Estado (...). Además, también hay un nivel cultural y un nivel de gente que te entiendes, no sé como... bueno un nivel medio culturalmente hablando, pero no lo sé, gente como yo, que hace que también te encuentres bien. (D4)

Esto hace que consideren que el municipio no sea comparable al resto del territorio, al menos de la región metropolitana de Barcelona. Una palabra recurrente en diferentes entrevistas es el de "burbuja": un espacio con unas características sociales, de paisaje y de vida totalmente distintas a las de su alrededor. En cierta forma, nos transporta al concepto de heterotopía de Foucaul, como un mundo inserido en otro y que, en cierta forma, es la materialización de la utopía (Solana, 2016).

Supongo que te lo deben haber dicho muchas veces que Matadepera es como una burbuja, ¿no? Es un pueblo a parte, es un lugar donde se vive muy bien y se vive al margen de todos los problemas que se puedan considerar que pueda haber en una gran ciudad o en una ciudad mediana. Mmmm, es un pueblo pequeño, con gente, la mayoría con una posición social muy acomodada. Y eso le da un aire de burbuja de... yo casi te diría que a veces pensamos como los niños. Es un poco irreal, ¿no? (D5)

2. Las entrevistas se realizaron en catalán. La traducción al castellano de las transcripciones la han realizado las personas que firman el artículo. 
Por eso, cuando se plantea a los informantes su opinión sobre la posibilidad que se densifique el casco urbano del municipio para contener la dispersión por el resto del término y dotar al municipio de mejores servicios (también de transporte) salen a relucir las resistencias, puesto que se teme que Matadepera pierda la categoría social actual.

Es lo que te decía, Matadepera, no creo que encajara bien, porque las personas y el talante de la gente que está viniendo es una y es un caché, si el ayuntamiento lo hace (aumentar la desidad) sería como bajar un poco el listón, yo creo..., es complicado. ¿Cómo lo vería yo? A mí no me gustaría. (D3)

\section{2. ¿Por qué? Motivos de la elección residencial}

Evidentemente, una de las razones para residir en las urbanizaciones del municipio la encontramos en la misma percepción que sus habitantes tienen de Matadepera. Pero cuando se les cuestiona directamente sobre los motivos de su elección aparecen elementos comunes en gran parte de los discursos.

Uno de ellos es la posibilidad de residir en una casa unifamiliar, preferiblemente aislada. Residir en un piso, con vecinos supone molestias, falta de espacio, de balcones, etc.: la opción de morar en una casa se adapta mejor a sus preferencias.

Estuve mirando unos pisos muy bonitos en Terrassa, pero de un piso a una casa me gustaba más la idea de una casa. ¿Por qué? Pues, no lo sé, eso del espacio verde... Quiero decir, tienes vecinos, pero ya están más lejos. (D13)

Un segundo elemento que aparece con mucha insistencia es el entorno natural. Cabe decir, que para las personas entrevistadas entorno natural se asocia a verde y especialmente a bosque, sin reparar en si este espacio forestal tiene un origen antrópico.

Claro, vivir en un entorno así, todos queremos vivir en un entorno así. Rodeado de verde y de naturaleza... Esto no tiene precio. Yo cuando veo esto y pienso, cuando era pequeño, yo quería vivir en un lugar así. (D5)

El tercer argumento compartido por las personas entrevistadas es la "tranquilidad". El sentimiento de tranquilidad es muy amplio y cada persona lo puede tener por un motivo distinto (incluso contrapuesto) esgrimido por otro individuo. En los relatos de las entrevistas, la tranquilidad se asocia al silencio, al poco movimiento, sin demasiadas actividades, alejado al trajín de las calles de los centros urbanos... En definitiva, trasluce un discurso antiurbano que presenta la ciudad como algo del que hay que huir.

Yo valoro mucho la tranquilidad, o sea realmente no oir los ruidos de la ciudad, todo eso que a mí me carga bastante. (D7)

También aparece en los discursos que la decisión de vivir en las urbanizaciones de Matadepera se toma en determinados momentos del ciclo de vida de las personas. Suele ser al cabo de un tiempo de vivir en pareja y sobre todo en el momento de tener hijos. Se quiere dar a estos un espacio propicio para su crianza y crecimiento, en un entorno natural (y social) amable, confortable y no agresivo para, en cierta forma, protegerlos de los "peligros" de la ciudad. Muchas de las personas entrevistadas cuentan que inicialmente vivían en la ciudad (normalmente en un piso) y que más adelante, por la ampliación de la familia y unido a la mejoría de la economía doméstica buscaban en un entorno suburbano una casa donde residir.

Cuando tienes hijos... pues tienes facilitades por ellos porque se pueden mover tranquilamente, hay seguriadad, es un pueblo pequeño, lo tienes todo más o menos cerca y porque es un lugar ideal, tienes naturaleza... (D1)

A pesar de esta voluntad de huir de la ciudad compacta, percibida como este lugar peligroso, contaminado, poco amable e incluso caótico, la elección de residir en una urbanización de Matadepera puede tomarse 
porque este municipio está plenamente integrado en un entorno urbano mucho más amplio cercano a Terrassa pero también a otros centros metropolitanos, incluida la misma Barcelona.

M atadepera es casi como un barrio de de Terrassa. (D11)

La elección concreta de Matadepera (en el conjunto de la Región Metropolitana de Barcelona existen más urbanizaciones de baja densidad con unas características similares) está determinada por la proximidad a la familia (en muchas ocasiones sita en el municipio de Terrassa) y por los antecedentes de relación con este entorno. Hay residentes que ya conocían la zona porque la familia tenía en ella la segunda residencia y era habitual veranear en el municipio. En este caso se trata de un proceso muy típico en numerosas urbanizaciones insertadas en entornos metropolitanos en el que el aumento de la población no se debe solo a la construcción de nuevas viviendas, sino que también por el paso de segundas residencias a primeras.

Yo soy de Barcelona, por eso, yo venía de veraneante. Mis padres eran de Barcelona, mi padre vendía por aquí parcelas y entonces lo que hacíamos era que los fines de semana, los sábados por la tarde, estábamos aquí y marchábamos los domingos a última hora, semanas santas, navidades, veranos aquí. (D3)

Este relato nos transporta a los orígenes de la suburbanización, a finales del s. XVIII, cuando la clase media decide trasladarse a las afueras de Londres, fuera de la contaminación y masificación, pero continuando en relación a ella (Muxí, 2012).

\section{3. ¿Qué estilo de vida? El village contra California}

La población que reside en las urbanizaciones, según se deprende de las entrevistas realizadas, son conscientes de su lugar de residencia dentro del municipio. Tienen claro que las urbanizaciones, por su estructura urbana, por su localización y por la distancia al centro del municipio tienen unas características distintas al casco urbano y con ello también el estilo de vida. Por tanto no se puede hablar de Matadepera en singular sino que, por las características morfológicas urbanas y por el uso del territorio que se hace en el municipio deben distinguirse tres distintas áreas: el centro urbano que tiene los atributos tradicionales de una ciudad, las urbanizaciones, y el espacio agroforestal utilizado intensamente por los residentes de fuera del municipio los fines de semana y que es cuando los habitantes de Matadepera se retiran porque lo encuentran sobrefrecuentado. Una informante lo relata así:

Veo que en Matadepera hay dos lugares, o tres, tres zonas distintas en Matadepera, hay el pueblo, que es como un mini Terrassa, donde vive mucha gente, tenemos los colegios y todos los servicios más o menos que necesitas y después están las zonas como aquí las urbanizaciones y la tercera es donde la gente viene a disfrutar de todo el paisaje los fines de semana normalmente y cuando yo no voy. (D9)

Si bien la distinción entre "pueblo" y "urbanizaciones" es compartido en todos los relatos, en algunos la distinción entre ellos no es tan categórica, sino que dibujan una gradación de mayor a menor vinculación de las urbanizaciones con el centro urbano (y por tanto con la vida municipal) a medida que aumenta la distancia entre estas y aquel. Esta vinculación significa una mayor integración en lo que se denomina la "vida de pueblo".

También hemos de considerar las urbanizaciones que hay en este pueblo (...) Por ejemplo, yo creo que a los de Pedritxes3 los tienen totalmente abandonados. Quiero decir... pertenecen a Matadepera pero es como si no pertenecieran a él, creo. Aquí, quieras o no, todavía tenemos algun vínculo con el pueblo. (D1)

3. Pedritxes es una urbanización del municipio. 
El hecho de residir en las urbanizaciones puede limitar la participación en la vida del pueblo: desde las compras cotidianas, pasando por la vida asociativa hasta las actividades de la fiesta mayor. Probablemente la mayor o menor participación en la vida del pueblo se modula a partir de diferentes factores: proximidad al núcleo urbano y por tanto sentirse, territorialmente, como parte de Matadepera, las historias personales de cada individuo (si se había residido anteriormente más en el centro, los años de residencia), la inclusión de los hijos en las actividades locales o la localización del puesto de trabajo. Pero los resultados muestran dos estilos de vida distintos y que coinciden con los descritos por Kaufmann (2000) para los entornos suburbanos. Por un lado, el modo de vida de "pueblo" (claramente minoritario) en el que se vinculan ciertas actividades en el ámbito local con desplazamientos en modos sostenibles (andando o bicicleta) pero con fuertes conexiones con el exterior realizadas de forma mayoritaria en vehículo privado. Este estilo de vida, según las personas entrevistadas, es más habitual entre los residentes en el centro urbano (a los que se les asocia como "vecinos de toda la vida") y para los habitantes de las urbanizaciones es más común entre los jóvenes, ya que en muchas ocasiones las actividades, tanto escolares como extraescolares, se llevan a cabo en el municipio. De otro lado, el modo de vida californiano propio de las urbanizaciones en la que el uso del coche es exclusivo y donde las relaciones cotidianas se desarrollan fuera del ámbito local. La única poca vida local en esta ocasión se centra en muchas ocasiones en las actividades de los hijos y las hijas, tanto escolares como extraescolares.

Como que bajamos a trabajar a Terrassa, claro, todo lo que sería a nivel de servicios, de cosas más utilitarias ya las hace en la ciudad (...) la gente que es del pueblo está vinculada a estas entidades y participa mucho, pero nosotros entre que llegamos hace poco y que vivimos en las afueras, no tenemos esta vinculación tan viva. (D12)

\section{4. ¿Inconvenientes? Los costes de residir en las urbanizaciones}

A pesar de los aspectos positivos expuestos para residir en Matadepera, el relato de las entrevistadas y entrevistados muestra cómo vivir en las urbanizaciones tiene unos costes. El que se percibe con más claridad y que aparece, sin duda, como el más importante y más común en todos los relatos es el transporte. Conforme a otros estudios (Miralles-Guasch y Cebollada, 2003) la percepción de los costes en los usuarios se centra en el temporal, mientras que otros costes como el monetario diferido y el coste asumido colectivamente (contamincación, salud, etc.) son ignorados. La necesidad de desplazarse para resolver los temas más cotidianos de la vida como es el acceso a los servicios, a las compras o al trabajo. Y que esta necesidad deba resolverse usando el vehículo privado (o en ocasiones la moto).

El hecho de tener que depender siempre de un transporte es el que a mi más me cuesta. Me cuesta más... Además, estaba en Terrassa antes de casarnos, vivía en el centro, cuando nos casamos vivía en el centro y claro, significa depender siempre del coche. Y realmente es lo que más me cuesta, me sigue costando. (D6)

Pero este coste se percibe mucho mayor cuando ya no se trata de garantizar el acceso a las actividades cotidianas propias sino del conjunto familiar y especialmente de los miembros menores de edad que no disponen de coche o moto para sus desplazamientos. Esta percepción parece que entra en contradicción con el argumento de que la decisión de residir en las urbanizaciones se hace por los hijos, pero al mismo tiempo es un engorro para ellos la falta de autonomía y para el conjunto familiar la logística de transporte que debe organizarse para garantizar el desarrollo de los quehaceres habituales de cada miembro de la familia.

Porqué vivo en esta urbanización que está bastante apartada del pueblo y hago muchos viajes en coche y lo único que a veces digo a los niños: me compraré una casa en el pueblo solo por los viajes. (D8)

Este coste de transporte se percibe aún mayor cuando los hijos e hijas llegan a la adolescencia y ya reclaman cierta autonomía que pueden ver limitada por las dificultades de desplazamiento. Y la percepción de que el problema se agranda se debe a dos causas. Por un lado, porque supone realizar desplazamientos 
"no previstos" o que son decisiones tomadas por el menor; y por otro también hay una preocupación por el sentimiento de aislamiento del adolescente, por su propio desarrollo.

No echo en falta nada, personalmente. Claro, mis hijos echan en falta el tema del transporte, es un hándicap, quizás el hándicap más importante porque es el que al final da la libertad de acción a todos a diferentes edades. (D12)

Más allá del coste que supone la dependencia del transporte, algunas entrevistadas viven contradictoriamente esta situación. Por una parte, ven la necesidad de contar con vehículo propio para resolver las necesidades de desplazamiento, pero por otra son conscientes que esto no es así en todos los entornos residenciales, que en un área compacta las necesidades de movilidad se resuelven mediante estrategias colectivas como es el uso del transporte público. Y, por tanto, se vive un forcejeo interno en que se asume que disponer de coche o moto no es la "normalidad" para todo el mundo y, al mismo tiempo, que supone un esfuerzo económico para la familia.

Jolín, quiero que tengan moto, pero es que lo tienen todo. ¿Cómo les doy a entender que les doy moto porque....? Si viviésemos en un lugar con transporte público no tendrían moto... (D2)

\subsection{La preponderancia del automóvil}

Como en cualquiera otra área residencial de baja densidad, la oferta de transporte mayoritaria es la del vehículo privado (Cebollada, Miralles-Guasch, 2010): la distribución de la calle, la oferta de aparcamiento, la red de carreteras y el parque de automóviles así lo indican. Los entrevistados lo muestran claramente cuando en todos sus hogares disponen, al menos, de dos vehículos (en algunos casos de empresa). Asimismo, todas las personas entrevistadas pueden usar el vehículo por su cuenta. Por tanto, es un colectivo que centra claramente su movilidad en el uso del coche. Este hecho es plenamente congruente con otros estudios: Navazo (2007) muestra como la oferta incentiva el uso del coche al carecer este de excesivas restricciones para su uso; Requena (2017) encuentra una relación directa entre la oferta de aparcamiento "libre" y prácticamente ilimitado con el uso del automóvil privado.

Los motivos esgrimidos para poseer, en los hogares, más de un vehículo privado es por la absoluta necesidad para desarrollar sus quehaceres cotidianos. Así, los adultos deben tener un coche a su disposición y los jóvenes cuando llegan a la mayoría de edad y van adquiriendo nuevas responsabilidades y sus vidas pasan por fuera del municipio (por ejemplo, ir a la universidad). En todo caso, los jóvenes pueden pasar por un periodo de uso de la moto.

¿Número de coches? Dos. Trabajando los dos y teniendo tres niños es imprescindible. (D5)

Todo es coche... y las niñas moto. (D2)

El uso del vehículo privado es para todo y siempre, incluso se utiliza cuando se considera que podría resolverse el desplazamiento de otra forma. Como se ha señalado anteriormente, las facilidades de uso del vehículo en las urbanizaciones son tan altas, que se va "en coche" en recorridos que probablemente por distancia se realizarían en modos no motorizados en un entorno urbano más denso y compacto.

Por ejemplo, ir a casa de mi padre que vive allí, pues voy andando y ostras es que está a diez minutos, quiero decir que tampoco está lejos, pero bueno, la pereza y la comodidad... y claro, tomo el coche. (D1)

La importancia del entorno urbano y de las posibilidades de desplazarse en coche se ve claramente cuando los informantes muestran que en los entornos en que el vehículo no es tan competitivo (congestión, dificultad de estacionamiento, pago para ello, etc.), las personas dejan el vehículo para continuar el viaje con otros modos. Por tanto, el coche se utiliza siempre en la etapa inicial del desplazamiento, pero para algunos 
de los viajes metropolitanos el automóvil sirve para llegar hasta la estación de ferrocarril más próxima (que está en Terrassa) y seguir con este medio el desplazamiento.

Entonces aprovecho la avenida Béjar, las Naciones Unidas, aparco por allí. Si puedo sí, y si no a veces voy con Salvador y vuelvo con Salvador. Pocas veces voy a Barcelona en coche, muy pocas. (D13)

Pero el uso continuo del coche no esgrime que también se perciban inconvenientes derivados de su uso. Además de algunas quejas por estacionamiento, el elemento que más aparece en los relatos de las entrevistas son los riesgos para las personas que no van en coche derivados de la velocidad de estos. El espacio público de las urbanizaciones, al carecer de las condiciones que Gehl (2010) describe para la vida social en la calle, incentiva las velocidades. Y esta percepción se da tanto en aquellas vías donde se cree que el flujo vehicular es relativamente alto (algunas calles, las carreteras que separan/unen las urbanizaciones), motivado por la orografía que hace que las calles tengan fuertes pendientes y curvas, por lo que la visibilidad por parte del resto de usuarios del espacio público es baja, así como, sin nombrarlo, por un diseño viario que invita a la velocidad. Todo esto hace que, cuando se puede, las personas que se desplazan con modos activos, busquen itinerarios alternativos para su propia seguridad.

Sí, pero tiene que bajar por la riera porque esta carretera es fatal, incluso pienso que Martí el próximo mes tendrá 15 años, pero debe tener moto, tengo mucho miedo, porque esta carretera de abajo es superpeligrosa. (D9)

Esta percepción de peligro se confirma cuando algún informante relata la existencia de accidentes de tránsito dentro de las urbanizaciones. En esta ocasión no se comentan daños personales, pero sí destrozos en la zona de jardín de la vivienda afectada.

Entró un coche por la esquina... o sea a las 7 de la mañana pasa el basurero, y vino una señora con un jeep a toda máquina, se encontró el camión y giró y entró. Y se empotró girada contra la encina. Tenemos una valla de alambre e hiedra. (D6)

La organización de la movilidad, y más en un entorno donde el modo de transporte mayoritario es el coche, requiere establecer estrategias compartidas para garantizar el acceso a los lugares de destino de todas las personas. En el caso de los residentes en las urbanizaciones de Matadepera, estas estrategias son básicamente familiares y se dan en el seno del núcleo del hogar. El montaje de estas estrategias se hace para los miembros que no disponen de vehículo ni pueden utilizarlo (los niños y niñas y las personas jóvenes). En este caso, solo se deben organizar estrategias si alguien, temporalmente, se quedara sin coche o no lo pudiera manejar. La necesidad de organizar estas estrategias y la falta de autonomía de los miembros que no pueden utilizar el coche hace que algunas informantes tengan la sensación que su "trabajo" sea el de taxista, es decir, el de ir "arriba y abajo" para que los menores puedan llegar a sus quehaceres.

Bueno de taxista, de pintora... jes que hago de todo! (D9)

Las estrategias de movilidad quedan en el seno familiar; Fox (1995) investiga la movilidad como una estrategia que afecta a todos los miembros de la familia, por lo que la introducción de nuevas necesidades de desplazamiento siginifica un reajuste en las pautas de movilidad del conjunto familiar como se muestran los resultados obtenidos eneste estudio. Si no es posible en el entorno del hogar pueden intervenir otros familiares próximos como abuelos o personas de confianza del hogar. En ocasiones puede ser la trabajadora que ayuda en las tareas domésticas.

Y los días que no podemos tenemos a Susana que es una señora que está con nosotros desde hace un montón de años que nos ayuda las tardes. Entonces, más o menos, lo tenemos cubierto. (D5)

Asimismo, llevar a cabo las estrategias de movilidad dentro del mismo seno de la familia significa acomodaciones horarias por parte de los diferentes miembros. En ocasiones puede ser que el menor se espere 
en el centro educativo, en equipamientos públicos (como la biblioteca), en casa de compañeros o que los adultos aprovechen para pasear o "hacer recados". Estas estrategias van disminuyendo con la edad de los menores; cuando estos van adquiriendo autonomía y pueden desplazarse por su cuenta (en modos activos o en transporte público) las estrategias colectivas se reducen a ciertas horas (por ejemplo, las nocturnas, cuando el servicio de autobús ha terminado) o estaciones (en invierno, por la menor presencia de personas, la menor duración del día, las bajas temperaturas... los menores "pierden" autonomía).

No mientras tenga alguien que lo vaya a buscar, el problema si tu quieres, es un inconveniente de hacerte cargo del chaval o de los críos, de bajar al pueblo a buscarlos a una hora determinada. Pero hasta las nueve no puede subir en bús, que tienes una hora prudencial, pero si van alargando un poco más, debes tirar de coche. Son cuatro kilómetros de aquí al pueblo y de subida. (D4)

Fuera del entorno familiar, pueden establecerse estrategias con otros hogares donde los menores compartan las mismas actividades y residan más o menos cerca unos de otros. Más extraño es establecer una estrategia con los vecinos para facilitar el acceso de los menores a sus actividades y descargar, así, a la familia de realizar todos los desplazamientos que estos deben hacer. Pero el testimonio de la persona que afirma que, al tener una furgoneta, se presta a llevar a otras personas para aprovechar el viaje, también afirma sin tapujos que nunca lo hace con los adultos.

Bueno como tengo la furgoneta, ya lo sabe la gente: sí yo siempre llevo niños arriba y abajo. ¡Pero con los adultos nunca! (D9)

Pero algunos estudios (Espluga et al. 2008) muestran como las estrategias de compartir automóvil por trayecto en zonas de baja densidad se da en los vecindarios antiguos que provienen de un pequeño núcleo rural, mientras que los que son fruto de la dispersión urbanas adolecen de lazos de vecindad y no comparten medio de transporte.

\subsection{Transporte público: entre la irrelevancia y el desconocimiento}

La oferta del transporte público en el municipio de Matadepera es percibida, en general, como muy baja. Esto se concreta en que se considera que ni la cobertura territorial por las urbanizaciones, ni la cobertura horaria ni la frecuencia de paso sirven para facilitar la movilidad alternativa al vehículo privado. Esta percepción del transporte público en las urbanizaciones hace que estos modos sean muy poco utilizados por los residentes.

No he tomado nunca el autobús, nunca, y las niñas creo que tampoco. (D2)

En referencia a la percepción de una cobertura territorial insuficiente deben tenerse en cuenta las características morfológicas de las urbanizaciones (baja densidad, lo que supone largas distancias con calles sin vida social) y orográficas (con fuertes desniveles, en gran parte de ellas). Tal como apuntan algunas fuentes, la eficacia del transporte público se relaciona, además de contar con una oferta suficiente, con la existencia de densidades de población mínimas (Riol, 2014). Esto influye tanto en alargar las distancias como en aumentar la percepción de distancia por el esfuerzo en las subidas como por la falta de un espacio público propiamente urbano.

Pero de los relatos también se extrae que hay un cierto desconocimiento del alcance real de la cobertura, especialmente horaria, del autobús que sirve a las urbanizaciones. Así, si bien los datos muestran unas frecuencias bajas (para nada comparables a las de los entornos urbanos centrales), sí que la tendencia es a percibirlo más deficiente. De hecho, algunas personas informantes reconocen que este bajo conocimiento también se debe a que no lo han necesitado: han organizado su quehacer cotidiano entorno al uso de su coche.

No, porqué nunca lo he necesitado. (D7) 
El desconocimiento de la oferta de transporte público no se reduce al de las líneas de autobús que sirven al municipio, sino también a la red de ferrocarriles que cubre la región metropolitana y que algunas de las personas entrevistadas utilizan.

De las entrevistas, se extrae que los que mejor conocen la oferta de transporte público son los jóvenes, hijos de las personas entrevistadas. Este hecho no debe extrañar, puesto que son los que posiblemente dependen más de este tipo de transporte para sus desplazamientos y quienes más lo utilizan en la familia. En todo caso, el conocimiento concreto de la oferta existente por parte de las personas entrevistadas, las posibilidades de desplazamiento y los enlaces necesarios para llegar a otros destinos metropolitanos se dejan para el futuro, para más adelante, cuando los hijos crezcan y necesiten hacer uso de esta red.

Hombre, de momento no lo necesitamos, pero más adelante cuando estudien fuera y eso, claro que sí. (D8)

Pero de las entrevistas también se extrae que hay conciencia de las dificultades de ofrecer un buen servicio de transporte público en el municipio sin que esto suponga un alto coste que a la postre se deberá asumir entre todos. Además de reconocer esta dificultad de servicio de medios colectivos en áreas de baja densidad, también se ve la incongruencia entre las reivindicaciones para tener un servicio de transporte público y que después, una vez conseguido, tenga que cerrarse por falta de usuarios; o sea, lo que este informante plantea es que la escasez de oferta pública de movilidad también es un efecto de la falta de demanda.

No hay, había, en Matadepera pusieron aquel microbús urbano y tal, e hicieron encuestas para ver si lo utilizaban. Hasta se recogieron firmas aquí en nuestro barrio para que pasara por allí y al final no se utilizaba, o sea que todos lo piden y al final ni Dios subía en aquel autobús. (D10)

Asimismo, en algunas entrevistas se muestra cómo la elección de residir en una urbanización imposibilita el uso del autobús como medio que permite acceder a bienes y servicios urbanos. Se piensa que los residentes en el centro urbano sí que tienen mayores posibilidades de uso puesto que la oferta para conectar la cabecera municipal con Terrassa es mayor.

Porque es una urbanización muy mal comunicada en transporte público. Claro, si estuviésemos en el pueblo, quizás sí que puedes utilizar el autobús. (D3)

La información recogida nos muestra que el autobús que presta servicio en las urbanizaciones lo usan las personas cautivas del transporte público. Un primer colectivo cautivo, como se ha comentado, son los menores de la familia. En este caso se asume que para ellos es un periodo transitorio en la vida de las personas, que a medida que alcancen la edad legal para conducir, se sacarán los permisos de circulación y adquirirán los vehículos. Muchas veces se empieza por la motocicleta para culminar con el automóvil privado. Por tanto, desde esta perspectiva, el autobús es una solución temporal para estos menores (y siempre que no pueda establecerse una estrategia que les permita ir de acompañante en coche).

Desde Matadepera, pocas veces hemos tomado el autobús, Irene puede que alguna vez: en principio cuando no tenía coche lo cogía de vez en cuando. (D10)

Pero, por los relatos, el colectivo que más utiliza el autobús son las trabajadoras de la limpieza doméstica, que son personas no residentes en el municipio. Este colectivo, que sale reiteradamente en los relatos de los informantes, era también el que mayoritariamente utilizaba el servicio de autobús que recorría las urbanizaciones ${ }^{4}$ y que en el momento de realizar el trabajo de campo para esta investigación ya no funcionaba.

A las nueve de la mañana vienen las trabajadoras, no son gente que vive en Matadepera. (D9)

4. Se trata de una línea de autobús municipal que recorria las urbanizaciones y lo conectaba con la cabecera de municipio. En el momento de realilzar el trabajo de campo esta línea había sido eliminada. 
Había un autobús antes que era una lanzadora desde el pueblo y recorría las urbanizaciones. Nos era muy práctico para la señora de la limpieza. Nosotros no lo habíamos tomado nunca. Per a la señora de la limpieza la dejaba exactamente aquí, delante de la puerta... Y también la recogía delante de la puerta...Duró... ¿un par de años? (D6)

\subsection{Movilidad activa para ocio y deporte}

Podríamos decir que la oferta de la movilidad activa es la gran ausente en la información de las entrevistas. La necesidad de infraestructuras para este modo de movilidad está muy poco presente en el imaginario de la población de las urbanizaciones que asume el uso del coche como absolutamente necesario y al que ya se han adaptado. Cabe decir, que esta adaptación tampoco requiere de grandes esfuerzos, puesto que la movilidad del automóvil no está en absoluto restringida, ni el ámbito circulatorio, de estacionamiento, de pago o con medidas ambientales.

En los relatos se reconoce que las aceras de las urbanizaciones están en mal estado y llenas de impedimentos, algunos estructurales como son la ubicación de los postes de electricidad. Pero, como se acaba de mencionar, se asume que no es necesario mejorar esta situación porque se utilizan muy poco y cuando se hace se camina por la calzada por el poco tráfico existente. Evidentemente, esto supone una exposición de riesgo para el peatón. En ningún momento, asumiendo este argumento, las personas entrevistadas exponen la necesidad de calmar el tráfico para hacer más seguro el desplazamiento andando, ya sea con medidas más fáciles y económicas como poner obstáculos en la calzada para reducir la velocidad de los automóviles u otras más costosas como hacer calles de un único nivel. Incluso, algunas de las personas entrevistadas consideran que invertir en mejorar la infraestructura para los peatones (como es la iluminación de las calles con la mejora de seguridad en la movilidad a pie) es innecesario. Este discurso se contrapone a los resultados de Héran (2018) según el cual los residentes de periferias bienestantes francesas reclaman mejoras en el espacio público para los modos de movilidad activos.

El relato cambia cuando se habla del casco urbano del municipio, y se distingue claramente de las urbanizaciones. En estas no hace falta aceras porque de allí uno sale o llega en coche, pero en las calles del pueblo las aceras son necesarias y, además, se recomienda que se mejoren y amplíen.

Es tirar dinero, creo que aquí las aceras no son necesarias; al pueblo sí, claramente, iy lo más anchas posible!, pero aquí en las urbanizaciones no. (D9)

Se percibe que un pueblo sin un centro peatonal es poco atractivo. Las áreas de peatones, se considera, embellecen el entorno urbano, le dan calidad. Pero se percibe más para un tema de ocio, de paseo, que como una infraestructura para la movilidad cotidiana, que conecte puntos y que tenga una lógica de itinerario.

Ahora que pusieron la zona peatonal... cuando llegué aquí, otra cosa que eché en falta de Matadepera, pensé ¿cómo que este pueblo no tiene núcleo? O sea, aquello que decías, si no se podía pasear, la calle Sant Joan era.. y que lástima porque ahora no es feo, es bonito y lo comentábamos con Alex que nos llamaba la atención, que hay pueblos cutres por ahí donde te sientes a gusto paseando porque ahora lo han arreglado la verdad es que está mucho mejor... pero no, no soy de pasear mucho por el pueblo tampoco. (D2)

Solo aisladamente aparece la reivindicación para la mejora de las conexiones de las urbanizaciones con el resto del municipio. Estas perspectivas se refieren a algunas áreas no urbanizadas del municipio, la pacificación de la carretera o, al menos, dotarla de algún sistema para cruzarla de forma segura e incluso la construcción de un carril bici que una las urbanizaciones más alejadas (o, al menos, las que no tienen una continuidad física con el núcleo y se debe utilizar la carretera para acceder a este). 
Es una zona que está muerta, quiero decir que los que juegan a golf no es productivo, si eso, por ejemplo, lo edificaran o hicieran por ejemplo como un parque o tipo zona Vallparadís5 donde hay puentes que lo conecten, para mí sería fantástico, y creo que toda esta gente también dejaría que los niños bajasen solos al pueblo. (D1)

Por tanto, los desplazamientos en modos de movilidad activa por parte de la población adulta son poco numerosos (casi testimoniales) para acceder a los puestos de trabajo o a los servicios o equipamientos necesarios para resolver las necesidades de la vida cotidiana. Solo una de las personas entrevistadas afirma que a veces va en bicicleta al trabajo, y que debido a la distancia y desniveles existentes en la ruta lo hace en una bicicleta eléctrica.

Pero dejando aparte este caso, el uso de los modos de movilidad activos responde a una necesidad de ocio: pasear y/o hacer deporte. Esta actividad se lleva a cabo en el entorno no urbanizado del municipio, por los espacios forestales. De hecho, es congruente con uno de los principales motivos que se esgrime como razón para residir en las urbanizaciones: la proximidad con la naturaleza. Según Muxí $(2012,11)$ se trata de un mitificado equilibrio entre ciudad y naturaleza cargado de "significados falaces".

Estos paseos son habituales entre las personas entrevistadas, puesto que muchas de ellas tienen perro; este hecho se esgrime frecuentemente como elemento que obliga o al menos incentiva a salir a pasear por el entorno forestal.

Sí, sí, tenemos el perro que nos obliga y nos va bien, porqué es llegar de trabajar y ya sales, al cuello de la Tartana arriba y ya te vas hacia Can Torras o hacia Can.... O sea, el bosque lo tienes a cinco minutos y esto es lo que más se valora. (D13)

En menor medida, el paseo por el entorno urbano es mucho más reducido. En algunos casos se relata el paseo por el núcleo urbano o el deplazamiento hasta Terrassa. En cambio, el paseo por el entorno más próximo, en la misma urbanización, se evita. Diríamos que por este entorno más próximo se "pasa" camino del entorno forestal. En estos espacios la calle no se percibe como espacio público y queda muy alejada de los atributos que le dotan de vitalidad según los criterios de Jacobs (2011) y Delclòs-Alió y Miralles-Guasch (2018).

Andar por la urbanización, a veces Montse me dice: ‘ivamos a andar!' ‘Dónde vamos a andar?’ ‘Por aquí la urbanización'.... Olvídate, es que yo andar por aquí... es que lo encuentro aburrido. (D11)

En el área de estudio, son los menores los que más se deplazan en los modos activos para acceder a sus actividades cotidianas. Son ellas y ellos los que incorporan esta forma de movilidad como una alternativa habitual para desplazarse por su entorno de vida. Esta forma de desplazarse es valorada positivamente por parte de los adultos. Se ve como una forma de ganar autonomía, de aprender a "moverse" solos y de ir cortando la dependencia con los adultos.

Que bajen andando. A mí me gusta... Ya no es por el hecho de caminar, sino por el hecho que no dependan de nosotros. (D7)

Pero la realización de esta actividad, en parte parecido al uso del autobús, se ve limitado por una serie de condicionantes. Uno de ellos es la edad de los menores; hasta cierto momento los padres no consideran que puedan ir solos andando o en bici. Otra condicionante es la estación del año y con ella, la mayor o menor duración del día, la temperatura, la sensación de mayor o menor amparo... hacen que el uso de los modos de movilidad activa se realice o no. Un tercer condicionante es la orografía. Por esto es habitual que los menores vayan al centro urbano (que es de bajada) en modos activos y el regreso se organice en el coche de alguien de la familia. Finalmente, el último de los condicionantes aparecidos en los relatos son las características del entorno urbano; en este caso, la falta de control social en el espacio, la falta de urbanización y

5. Vallparadís es un parque urbano de la ciudad de Terrassa. 
la percepción de riesgo en algunos puntos por el tráfico motorizado desaconsejan el caminar o el ir en bici. Como afirma Gehl (2010), la actividad y la presencia de personas en la calle, en el espacio público, es la mejor forma de atraer a más personas y actividades.

Una vez más, el núcleo del municipio es percibido como un lugar ideal para que los niños y niñas puedan pasear solos. Los atributos que faltan en las urbanizaciones, se encuentran en la cabecera del municipio.

Aquí por ejemplo en Matadepera puedes dejar que los niños corran por el pueblo. Yo, en Barcelona no dejaría ir a mi hijo. Ve, ve. Nos vemos aquí en una hora y media. No ... no me atrevería. En cambio, en Matadepera sí. (D5)

\section{CONCLUSIONES}

La investigación llevada a cabo ha permitido dar respuesta a las preguntas planteadas en un inicio sobre las pautas de movilidad de los residentes, las percepciones y expectativas que tienen acerca de la movilidad, los factores que explican los hábitos y la presencia de nuevas narrativas de movilidad en el imaginario y la vida cotidiana de los residentes.

Los resultados muestran unas pautas de movilidad dominadas ampliamente por el automóvil. Su uso es omnipresente, así como su oferta: en los hogares de todas las personas entrevistadas hay como mínimo dos automóviles. El uso de medios alternativos al coche aparece marginalmente en los relatos y habitualmente se utilizan fuera del entorno inmediato de residencia.

El principal factor para comprender el uso masivo del vehículo privado son las propias características morfológicas. Así se explican los hábitos (y también las percepciones) distintas entre urbanizaciones y núcleos urbanos. Mientras que en las zonas de baja densidad las perspectivas de uso del transporte público son escasas, en áreas más densas y congestionadas el uso de los transportes colectivos masivos (especialmente los ferrocarriles) es una alternativa real y practicable al uso del coche. Asimismo, además de la morfología, la falta de un diseño adecuado en las urbanizaciones desincentiva el uso de los modos activos de movilidad: pacificación del tráfico, permeabilidad entendida como la facilidad de cruzar las vías con alta densidad de tráfico, urbanización e infraestructura ciclable son los elementos que se echan en falta.

Un segundo factor que conforman las pautas de movilidad de la población es el social. En ocasiones, el colectivo de pertenencia juega un papel central en la configuración de los hábitos de movilidad incluso en espacios tan propensos al uso de coche. Colectivos que podríamos considerar no hegemónicos, e incluso uno de ellos socialmente cuasi marginal, en las urbanizaciones son cautivos de los modos alternativos al automóvil. Por un lado, los menores que ven en el andar, la bicicleta y el transporte público recursos temporales antes de acceder autónomamente a un modo individual motorizado. Por otro lado, las trabajadoras domésticas de la limpieza son el otro colectivo cautivo del transporte público y las principales perjudicadas en la disminución de su oferta.

Asimismo, la investigación ha servido para resaltar la falta de uso y expectativas de los nuevos modos activos de movilidad presentes en las narrativas de las zonas urbanas más densas como son los patinetes, skate y las distintas variantes de ellos. Parece que en estos ámbitos territoriales las nuevas tendencias de movilidad urbanas no pueden permeabilizar.

Asimismo, los residentes en estas urbanizaciones no incluyen en sus narrativas el cambio de concepción de la movilidad, entendida esta como un servicio. En este caso, el paso de la propiedad (principalmente del coche) hacia el concepto de compartir (concretizado en formas diversas como pueden ser nuevas empresas de movilidad o nuevas formas cooperativas) tampoco tienen cabida, por ahora, en estos espacios de baja densidad.

En definitiva, la investigación no muestra indicios de cambio en los hábitos modales entre los residentes de las áreas urbanas de baja densidad bienestantes como sucede en ámbitos centrales de las áreas urbanas densas. Probablemente, las políticas públicas locales deben dirigirse a crear las condiciones necesarias para el cambio modal y de hábitos a partir de acciones que creen proximidad, diversidad, redistribuyendo prioridades en el espacio público en favor de los modos alternativos al vehículo privado y visibilizando los costes globales del transporte motorizado. 


\section{Agradecimientos}

Esta investigación se ha realizado con financiación recibida por parte de la Secretaría de Estado de Investigación, Desarrollo e Innovación (CSO2015-65257-R) y la Agència de Gestió d'Ajuts Universitaris i de Recerca (AGAUR-2017 SGR-343 and AGAUR-2014 SGR-553 1090).

\section{REFERENCIAS}

Aguilar, R. (2012). Memòries d'una feixa. la urbanització d́ un poble pagès de la regió de Barcelona (Matadepera, 1931-1983). Matadepera: Ecos S.C.C.L. - Publicacions d'economia Solidària.

Barba, J. y Mercadé, M. (2006). Les urbanitzacions a la província de Barcelona. Barcelona: Diputació de Barcelona.

Braçe, O. (2018). Efectos de la Expansión Urbana en la Elección de los Modos de Transportte Utilizados para los Desplazamientos Diarios en Áreas Metropolitanas. Un Estudio de Caso. Revista de Estudios Andaluces, 38, 208-221. doi: http:// dx.doi.org/10.12795/rea.2018.i36.09

Casanovas, R. y Gutiérrez, B. (2012). La vida cotidiana en las áreas residenciales monofuncionales de baja densidad. En Z. Muixí (Coord.) Postsuburbia. Rehabilitación de urbanizaciones monofuncionales de baja densidad (pp. 25-35). Barcelona: Comanegra.

Castillo, J.M. (2011). Migraciones ambientales. Barcelona: Virus.

Cebollada, À. (2009). Mobility and labour market exclusion in the Barcelona Metropolitan Region. Journal of Transport Geography, 17, 226-233. doi: https://doi.org/10.1016/j.jtrangeo.2008.07.009

Cebollada, À., Miralles-Guasch, C. (2010). La movilidad en la región moetropolitana de Barcelona: entre los nuevos retos y las viejas prácticas. Finisterra, XLV, 90, 33-47.

Delclòs-Alió X., Miralles-Guasch C. (2018). Looking at Barcelona through Jane Jacobs's eyes: Mapping the basic conditions for urban vitality in a Mediterranean conurbation. Land Use Policy, 75, 505-517. doi: https://doi.org/10.1016/j.landusepol.2018.04.026

Departament de Territori i Sostenibilitat, (n.d.). Urbanitzacions. Recuperado en diciembre de 2019 de http://territori.gencat.cat/ca/06_territori_i_urbanisme/urbanisme/urbanitzacions/.

EEA, (2006). Urban sprawl in Europe. The ignored challenge No 10/2006. Copenhagen: European Environmental Agency.

Espluga, J. L., Cebollada, À., Miralles-Guasch, C. (2008). Percepciones de la movilidad y participación en la región metropolitana de Barcelona. Ciudad y Territorio. Estudios territoriales, XL (157), 499- 510.

Fàbregas, C., Villalante, M. (2017). Mobilitat com a servei: l'eclosió de la transformació digital del transport. Papers $n^{\circ} 59$, Nous reptes en la mobilitat quotidiana. Polítiques públiques per a un model més equitatiu i sostenible, 152 - 163.

Font, A. (2007a). Región urbana de Barcelona: de la Ciudad compacta a los territorios metropolitanos. En: F. Indovina (Coord.) La Ciudad de baja densidad. Lógicas, gestión y contención (pp. 27 - 50). Barcelona: Diputació de Barcelona.

Font, A. (2007b). Morfologías metropolitanas contemporáneas de la baja densidad. En: F. Indovina, (coord.) La Ciudad de baja densidad. Lógicas, gestión y contención (pp. 97 - 108). Barcelona: Diputación de Barcelona.

Fox, M. (1995). Transport planning and the human activity approach" Journal of Transport Geography, 3 (2), p. 105 - 116. doi: https://doi.org/10.1016/0966-6923(95)00003-L

García Palomares, J.C. (2008). Los desplazamientos al trabajo en la Comunidad de Madrid. Madrid: Fundación Sindical de Estudios.

García, E. (1999). La sostenibilidad de las ciudades y la organización social de la movilidad. Ecología política, 17, 55-68.

Gehl, J. (2010). Cities for People. Washington, Covelo, London: Island Press.

Héran, F. (2018). Les difficultés de la transition écomobile. En: N. Baron y J. Romero (eds. Cultura territorial e innovación social. ¿Hacia un nuevo modelo metropolitano ne Europa del Sur? (pp. 271-280). València: Publicacions de la Universitat de València.

IDESCAT (2016). Renda familiar disponible bruta territorial. 2016. Recuperado en mayo de 2019 de Barcelona: IDESCAT, https://www.idescat.cat/novetats/?id=3250

Jacobs, J. (2011). Muerte y vida de las grandes ciudades. Madrid: Capitán Swing. (Original de 1961 The Death and Life of Great American Cities). 
Kaufmann, V. (2000). Mobilité quotidienne et dynamiques urbaines. La question du report modal. Lausane: Presses polytechniqueset universitaires romandes. doi: https://doi.org/10.1016/S0761-8980(00)90032-3

Kingley, D., Urry, J. (2011). Un mundo sin coches. Barcelona: Península.

Lelieveld, J., Klingmüller, A. P., Pöschl, U., Fnais, M., Daiber, A. \& Münzel, T. (2019). Cardiovascular disease burden from ambient air pollution in Europe reassessed using novel hazard ratio functions. European Heart Journal, 135, 1-7. doi: https://doi.org/10.1093/eurheartj/ehz135

Meadows, D.H., Meadow, D.L., Randers, J. \& Benhrens, W. W. (1972). Los límites del crecimiento. México D.F.: Fondo de Cultura Económica. (Original de 1972 The Limits of Growth).

Mendiola, L. (2011). Transformación urbana y movilidad en los municipios de Bizkaia (1991 - 2001). Bellaterra: Universitat Autònoma de Barcelona (Tesis de doctorado).

Mendiola, L., González, P. y Cebollada, À. (2014). The link between urban development and the modal split in commuting: the case of Biscay. Journal of Transport Geography, 37, 1-9. doi: https://doi.org/10.1016/j.jtrangeo.2014.03.014

Miralles-Guasch, C. (2010). Dones, mobilitat, temps i ciutat. Barcelona: Institut Català de les Dones.

Miralles-Guasch, C. y Cebollada, À. (2003). Movilidad y transporte. Opciones políticas para la ciudad. Madrid: Fundación Alternativas. Documento de trabajo 25/2003.

MUC, Mapa Urbanístic de Catalunya. Recuperado en mayo de 2019 de http://territori.gencat.cat/ca/06_territori_i_urbanisme/observatori_territori/mapa_urbanistic_de_catalunya/.

Muñoz, F. (2005). La producción residencial de baixa densitat. Barcelona, Diputació de Barcelona.

Muñoz, F. (2007). La producción residencial de baja densidad en la provincia de Barcelona (1585-2001) En: F. Indovina (Coord.) La Ciudad de baja densidad. Lógicas, gestión y contención (pp. 51 - 84). Barcelona: Diputació de Barcelona.

Naredo, J. M., Frías, J. (2007). El metabolismo económico de la conurbación madrileña (1984 - 2001). En: F. Indovina, (Coord.) La Ciudad de baja densidad. Lógicas, gestión y contención (pp. 131 - 184). Barcelona: Diputación de Barcelona.

Navazo, M. (2007). Décalogo para re-enfocar las políticas de movilidad. Ciudades para un Futuro más Sostenible, 35. Recuperado en diciembre de 2019 de http://habitat.aq.upm.es/boletin/n35/amnav.html.

Nello, O., López, J. y Piqué, J.M. (2002). Las redes emergentes de articulación de territorio en la región de Barcelona: un análisis de la movilidad obligada, 1986 -1996. En J. Subirats (Coord.) Redes, territories y gobierno (pp. 201-221). Barcelona: Diputació de Barcelona.

Pooley, C.G. \& Turnbull, J. (1999). The journey to work: a century of change. Area, 31 (3), 281-292. doi: https://doi.or$\mathrm{g} / 10.1111 / \mathrm{j} .1475-4762.1999 . t b 00092 . x$

Prats, F., Herrero, Y., Torrego, A. (2017). La gran encrucijada. Sobre la crisis ecosocial y el cambio de ciclo histórico. Madrid: Libros en acción.

Requena, R. (2017). Análisi de la gerstió del transport privat en un pol de coneixment metropolità. El cas de la Universitat Autònoma de Barcelona. Bellaterra, Tesi Doctoral. Recuperado en diciembre de 2019 de https://www.tesisenred. net/handle/10803/459152\#page=1.

Richier, C., Rabaud, M. (2018). Modes actifs au centre, voiture en péripherie: un modèle de mobilité ineluctable pour la metropole de Lille? En: N. Baron y J. Romero (Eds). Cultura territorial e innovación social. ¿Hacia un nuevo modelo metropolitano en Europa del Sur? (pp. 307-327). València: Publicacions de la Universitat de València.

Riol, R. y Luján, X. (2014). TREN 2020. Propuesta ferroviaria para una nueva realidad. Madrid: CCOO, Greenpeace, WWF, PTP. Rodríguez, G., Gil, J. y García, E. (1996). Metodología de la investigación cualitativa: Archidona, Aljibe.

Rueda, S. (2017). Les superilles per al disseny de noves ciutats i la renovació de les existents. El cas de Barcelona. Papers $n^{\circ}$ 59, Nous reptes en la mobilitat quotidiana. Polítiques públiques per a un model més equitatiu i sostenible, 78 - 93.

Ruiz, J.I. (1996). Metodología de la investigación cualitativa: Bilbao, Universidad de Deusto.

Solana, M. (Coord.), Badia, A., Cebollada, À., Ortiz, A. y Vera, A. (2016). Espacios globales y lugares próximos. Setenta conceptos para entender la organización territorial del capitalismo global. Barcelona: Icaria.

Stehlin, J. (2015). Cycles of investment: bicycle infrastructure, gentrification, and the restructuring of the San Francisco Bay Area. Environment and Planning A, 47, 121-137. doi: https://doi.org/10.1068/a130098p

Valles. M. S. (1997). Técnicas cualitativas de investigación social. Reflexión metológica práctica profesional: Madrid, Síntesis WHO (2016). Ambient air pollution: A global assessment of exposure and burden of disease. Geneva: World Health Organization. 